\title{
Numerical studies on two-tiered MSE walls under seismic loading
}

\author{
Ananya Srivastava $^{1}$ (D) Vinay Bhushan Chauhan ${ }^{1}$ (D)
}

Received: 23 March 2020 / Accepted: 23 August 2020 / Published online: 3 September 2020

(c) Springer Nature Switzerland AG 2020

\begin{abstract}
Mechanically Stabilized Earth (MSE) retaining walls, reinforced by the geogrids and using rigid segmental blocks as facing elements have extensively been used in recent past as an economic and sustainable solution for the earth retention. Nevertheless, in the case of a high retaining wall, tiered walls are preferred than a single-tier retaining wall due to their cost-effectiveness and more stability than single-tiered MSE walls. However, the behavior of tiered MSE retaining wall under dynamic loading is not yet studied thoroughly as the conventional design in practice is based on offset distance between the tiered walls and certain assumptions of surcharge loading imparted by the weight of tiered walls itself. Therefore, an attempt has been made to examine the behavior of tiered MSE retaining wall using finite element method, having a height of $12 \mathrm{~m}(\mathrm{H})$ under gravity and seismic loading to compare its stability with the conventional (single-tier) MSE retaining wall in terms of factor of safety (FOS) and to look into the possible modes of failure. The factor of safety shows a raise of $66 \%$ in two-tiered walls, when the horizontal seismic acceleration coefficient $\left(k_{h}\right)$ is 0.36 for both the walls, during the analysis of single-tiered and two-tiered wall systems. An optimum reinforcement length is evaluated for two-tiered wall system under seismic and static loading conditions. It is suggested that reinforcement $0.8 \mathrm{H}$ and $1.1 \mathrm{H}$ is suitable in two-tiered MSE walls, under static and dynamic loading respectively.
\end{abstract}

Keywords MSE retaining walls · Finite element method $\cdot$ Tiered wall $\cdot$ Seismic loading $\cdot$ Failure plane

\section{Introduction}

Often, it is observed that for very high retaining structures, poor/soft soil strata is not preferred for foundation, as it may lead to higher settlement with lower factor of safety of the overall structure. In such conditions, the technique of soil reinforcement is practiced to construct several cost-effective retaining structures such as retaining walls, bridge abutments etc. in an environment friendly and sustainable method. The commonly preferred reinforcement materials are galvanized steel strips, geosynthetics (in the form of woven geotextiles), geogrids and geocomposites, and fibers from natural and waste products. Reinforcements in the soil can improve the overall stability of the load-bearing structures constructed over the soil mass by using tensile reinforcements in the form of geogrid, when the load-bearing structure is subjected to static and dynamic loading conditions. The previously available literature from past studies and the current design methodologies followed during the construction of reinforced earth structures shows that the provision of reinforcement causes an increment in the load bearing capacity and enhanced overall stability of the retaining structure.

In such cases, tiered MSE walls may prove a safer structure as they will disperse the load on a larger area, leading to a safer solution for earth retaining structures.

Mechanically Stabilized Earth walls are the most common reinforced earth retaining structures. They can withstand much higher surcharge loads and have significant technical and cost advantages over conventional earth retention systems i.e. reinforced concrete retaining walls. In case of high retention of earth mass, MSE walls require

$\triangle$ Vinay Bhushan Chauhan, vbcce@mmmut.ac.in; Ananya Srivastava, ananyashri.work@gmail.com| ${ }^{1}$ Civil Engineering Department, Madan Mohan Malaviya University of Technology, Gorakhpur 273010, India. 
a high volume of excavation to lay the reinforcing layer (geogrids), which requires a large land space behind the wall for the positioning of the reinforcing layer effectively. Sometimes, the unavailability of land space required for the placement of the reinforcing layer behind the wall requires an alternative solution because to economize the overall project cost, effective utilization of land space is an essential key. In such conditions, an alternative solution is to construct MSE walls in a tiered configuration because they are practical to construct, structurally sound, economical, aesthetically pleasing, environmentally consistent with the surroundings, and have minimal maintenance problems [1].

A tiered retaining wall system is a series of two or more stacked walls at different levels, where each tier is placed on the backfill surface of the preceding tier and spaced apart at a certain offset distance. When designed suitably, they not only retain the backfill and support the loads but also deliver an attractive appearance and provide room for plantation. This results in a wall having the desired overall height with reduced reinforcement stresses. If the offset is large, each tier may perform internally independent of the other tiers. However, the overall global (slope) stability might be affected $[2,3]$.

The design methods for 2-tiered and multi-tiered MSE retaining walls are suggested in FHWA [4], NCMA [5], and AASHTO [6], to determine the offset distances of multitiered-reinforced soil walls. The upper tier, of a 2-tiered MSE retaining wall, can be treated as an equivalent surcharge, and its magnitude is determined according to the offset distance as mentioned in NCMA.

In AASHTO [6] guidelines, the two tiers in a tiered wall system are considered to be independent of each other if the offset distance between the two tiers is greater than $H_{\mathrm{m}} \tan \left(90-\phi_{\mathrm{r}}\right)$, where $H_{\mathrm{m}}$ is the height of lower-tier and $\phi_{\mathrm{r}}$ is the angle of internal friction of the reinforced soil backfill. Previous studies on multi-tiered-reinforced soil walls have shown that an increment in offset distance reduces the required reinforcement load and facing displacement. These studies demonstrated that the interaction between upper and lower tier creates an effect on the performance of the lower tier. The multi-tiered configuration could considerably reduce the residual lateral facing displacement and the average reinforcement load. In such cases, external and internal stability calculations of the lower-tier are performed assuming lower-tier being a single wall under the equivalent surcharge [7].

The analysis and design of tiered MSE retaining walls are often more complex than the conventional MSE retaining walls. In contrast, reinforcement parameters (length, vertical spacing, and stiffness) for tiered walls cannot be estimated using standard design charts. The behavior of tiered MSE retaining walls is complicated and unfortunately, their behavior in terms of performance under seismic loading has not been well-investigated in the available literature.

In view of above, the present study is aimed to assess the performance of a two-tiered MSE retaining wall each having a height of $6 \mathrm{~m}$ is compared with a $12 \mathrm{~m}$ high conventional MSE retaining wall with varying reinforcement length under static and seismic loading while evaluating their stability in terms of the factor of safety (FOS) and presents insight into the possible modes of failure of such complicated structures. For the abovementioned objective of the present study, a two-dimensional model is adopted for the simulation of the MSE retaining wall, and the analysis is carried out using the shear strength reduction method using the finite element analysis for the evaluation of the factor of safety of the MSE retaining wall system [8].

\section{Numerical modeling of MSE retaining wall}

In the present study, FHWA [4] recommendations have been followed to design the walls (spacing and length of reinforcement) and to examine the behavior under gravity and seismic loading using finite element modeling for various lengths of reinforcement. In the present study, various cases of MSE retaining wall (single-tier and twotier) are considered as a two-dimensional problem for the numerical modeling, as the plane strain conditions prevail in such retaining wall structures, which is best suitable for 2-dimensional analysis [9, 10] with sufficient accuracy and time-saving in the computational analysis. As per the guidelines of FHWA for the design of tiered MSE walls, which suggests that the individual walls in the tiered system can be treated as separate, independent walls when the offset distance, $D$, exceeds the following criterion:

$D=H_{m} \tan \left(90-\varphi_{\mathrm{r}}\right)$

where $H_{m}$ is the height of the lower of the two tiers and $\varphi_{r}$ is the friction angle for the reinforced soil backfill [4].

For the present study, a two-tiered superimposed MSE retaining wall and conventional MSE retaining wall reinforced using geogrid having a total height of $12 \mathrm{~m}$ with a rigid facing (concrete blocks) were considered to investigate their stability under gravity and seismic loading.

For the numerical simulation of the structure considered under the study, the actual stress path being experienced by the overall wall system in practice is being followed step by step as described below. A rigid leveling pad (concrete) with dimensions $2.0 \mathrm{~m} \times 0.2 \mathrm{~m}$ (in elevation) is laid on the foundation soil over which a rigid concrete facing with dimensions $1.5 \mathrm{~m} \times 0.6 \mathrm{~m}$ (in elevation) is laid and behind which a layer of backfill having a lift of $0.6 \mathrm{~m}$ 
is deposited. Before placing the next concrete block as a facing, a geogrid layer of the desired length, $L$ is placed on the finalized backfill surface in the previous lift such that a portion of geogrid length is well-clamped between the successive concrete facings. In the next step, the backfill layer is deposited over the geogrid layer is deposited behind the concrete facing and this procedure is repeated until the desired height of the wall is achieved. Here, the geogrid reinforcement is modeled as an elastic material to withstand the tensile load, and the backfill is considered as an elastoplastic material that follows the Mohr-Coulomb model.

The force transfer mechanism between two dissimilar materials is simulated as an elastoplastic interface and appropriate interface coefficient values are assigned at all the interfaces in the MSE wall system. The interface coefficients for concrete block-geosynthetic interface and soilgeosynthetic interface are taken as 0.8 and 0.65 , respectively. For the numerical analysis of geogrid-reinforced soil retaining wall, a series of organized simulations were executed using a finite element based computational tool Optum G2 [11] in the two-dimensional analysis [8].

The stability of the overall structure is evaluated using the strength reduction method and the factor of safety is calculated. The total height of the single-tier wall is considered as $12 \mathrm{~m}(\mathrm{H})$ and the height of the two-tiers for lower $\left(H_{1}\right)$ and upper $\left(H_{2}\right)$ tier is taken as $6 \mathrm{~m}$ each $\left(H_{1}=H_{2}=6 \mathrm{~m}\right)$. The offset distance between the two tiers is taken as $D=9 \mathrm{~m}$. Complete details of the geometrical configuration of single-tier and two-tiered MSE retaining walls reinforced with geogrid are shown in Figs. 1 and 2, respectively. Material properties used in the present study are shown in Table 1. To provide the adequate boundary conditions for the reinforced soil wall system, the bottom was kept fixed and roller supports were provided the vertical edges of the mesh.
To get an accurate result from the numerical analysis, the selection of an appropriate number of total elements in the mesh is the primary essential requirement in the numerical simulation a sensitivity analysis has been carried out.

Outcomes of the sensitivity analysis confirmed that 10,000 elements in the mess were found an appropriate choice for the mesh generated for the reinforced soil retaining wall system.

As per the suggestions laid by FHWA for multi-tiered walls, the range of geogrid reinforcement length in the lower and upper walls should not be less than 0.7 times of the individual wall height for static case restricted up to 1.1 times of the individual wall height [4]. NCMA [5] suggests that the length of reinforcement must not be less than 0.6 times the individual wall height. Therefore in this study the variation of reinforcement length ranges from 0.5 to 1.2 which covers both the criterion laid by FHWA and NCMA.

In the present study, the ratio of the reinforcement to the height of the wall ( $L / H$ ratio) is varied from 0.5 to 1.2 at an interval of 0.2 units. The variation of $L / H$ ratio has intentionally been considered for the cases $L / H<0.7$ and $L / H>1.1$, to have an insight into the generation of failure surfaces in the reinforced wall for the cases when reinforcing length is either insufficient or more than the required length.

The stability assessment of reinforced retaining wall for the case of conventional and two-tier under seismic loading is carried out for a range of horizontal seismic acceleration coefficient, $k_{\mathrm{h}}=0.12,0.24$ and 0.36 and compared with the non-seismic case, i.e. $k_{\mathrm{h}}=0$. Failure modes of the wall and their transition from one mode to another mode of failure due to the variation in the geogrid length configuration and horizontal seismic acceleration have been analyzed and presented in the next section.
Fig. 1 Typical mesh for a $12 \mathrm{~m}$ high single tier MSE retaining wall considered in the present study

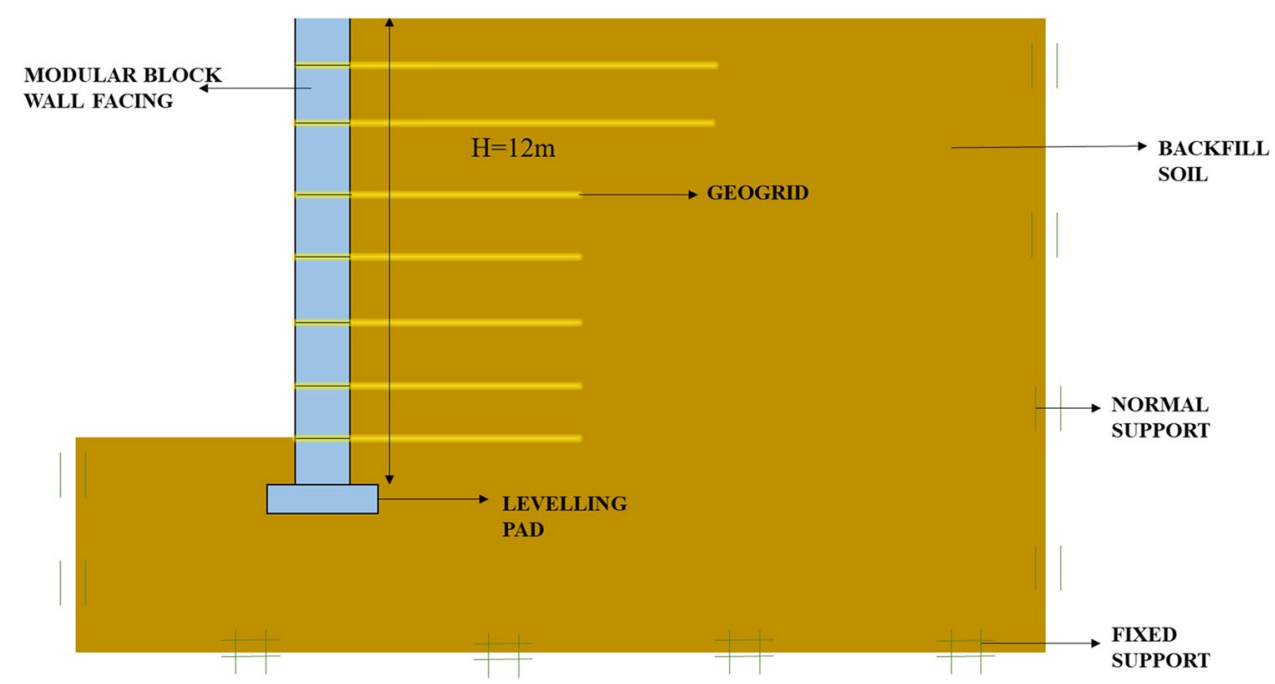

SN Applied Sciences A SPRINGER NATURE journal 
Fig. 2 Typical mesh for a twotier MSE retaining wall having a height of $12 \mathrm{~m}$ considered in the present study

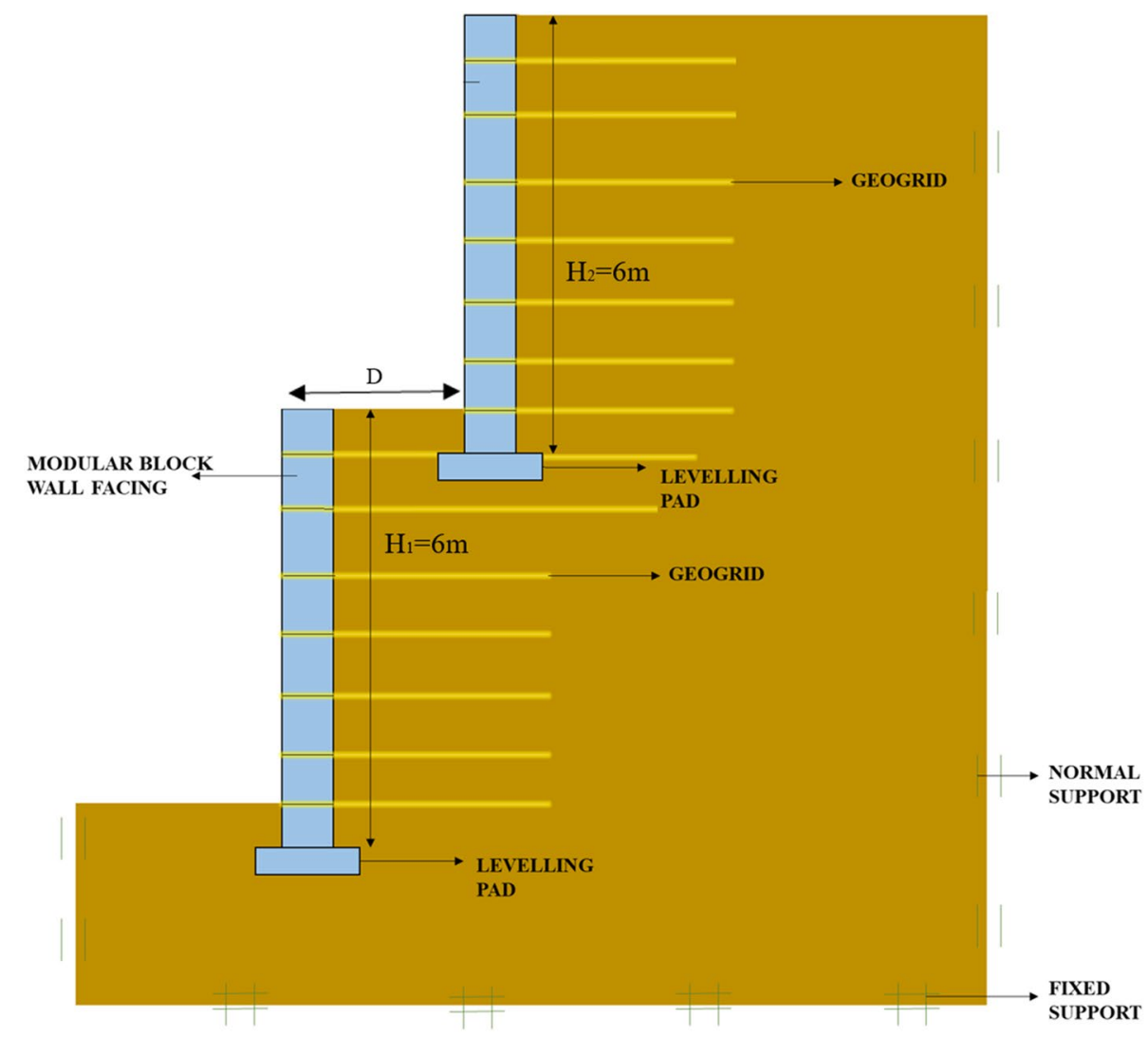

Table 1 Material properties considered in the present study

\begin{tabular}{lll}
\hline Property & Geogrid & Backfill material \\
\hline Stiffness $(\mathrm{kN} / \mathrm{m})$ & 880 & - \\
Yield force $(\mathrm{kN} / \mathrm{m})$ & 88 & - \\
Modulus of elasticity $(\mathrm{MPa})$ & - & 35 \\
Poisson's ratio & - & 0.25 \\
Cohesion $\left(\mathrm{kN} / \mathrm{m}^{2}\right)$ & - & - \\
Dry unit weight $\left(\mathrm{kN} / \mathrm{m}^{3}\right)$ & - & 16 \\
Internal friction angle $($ degrees) & - & 36.5 \\
Dilation angle (degrees) & - & 5
\end{tabular}

\section{Results and discussion}

From the numerical analysis carried out in the present study, the factor of safety of various wall systems is obtained by the shear strength reduction method and discussed in the following section.

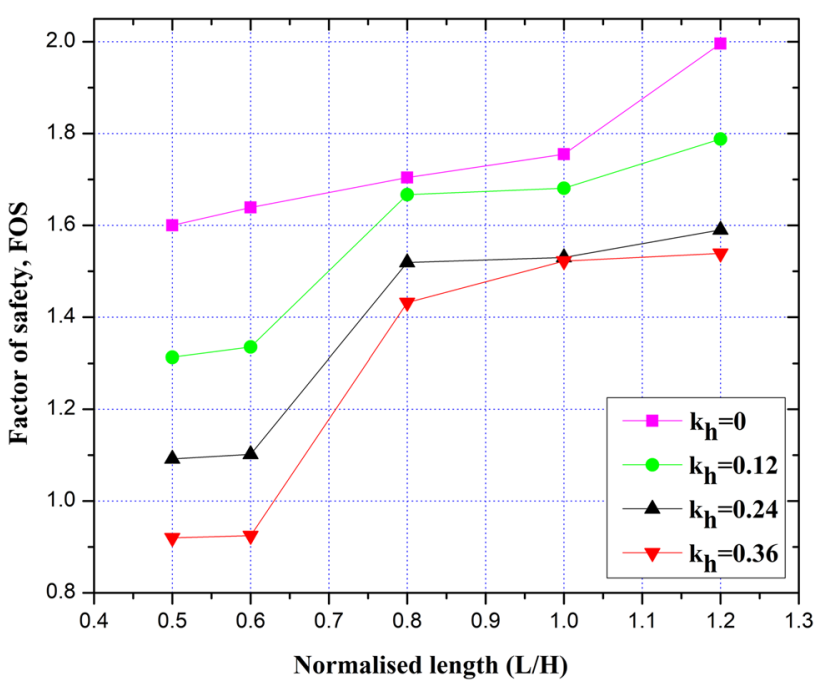

Fig. 3 Effect of variation of the horizontal seismic acceleration coefficient $\left(k_{\mathrm{h}}\right)$ in two tiered wall system

\subsection{Effect of variation of the horizontal seismic acceleration coefficient $\left(\boldsymbol{k}_{\mathrm{h}}\right)$}

The tiered wall system experiences some significant variations in FOS values due to the change in the horizontal seismic acceleration coefficient $\left(k_{\mathrm{h}}\right)$. Figure 3 
demonstrates the variation of FOS w.r.t various horizontal seismic acceleration coefficients $\left(k_{h}\right)$. As suggested by FHWA [4], for a safely designed wall system, the FOS value must not be lesser than 1.50, where the geotechnical parameters are based on limited information; and where the wall/slope contains or supports a structural element. In the two-tiered wall system, the best value of FOS obtained under gravity loading conditions is 1.99 , which is far above the required criterion and can be stated as a fine performance of the tiered wall system. With an increase in the $k_{\mathrm{h}}$ values, the FOS reduces to 0.92 . But, as stated by FHWA, for seismic loading conditions, the length of reinforcement must be greater than or equal to $1.0 \mathrm{H}$, so at the highest value of horizontal seismic acceleration coefficient, $k_{\mathrm{h}}=0.36$, the $L / H$ ratios falling under this criteria, i.e. $L / H=1.0$, and 1.2 , provide satisfactory values of FOS as 1.52 and 1.53 respectively, thus making this design safe and serviceable. The singletiered wall system with a total height of $12 \mathrm{~m}$ fails miserably in providing the required FOS, which is 1.031 , barely crossing the criterion for a safely designed wall. Again, as the $k_{\mathrm{h}}$ value increases from zero to 0.36 , a drastic fall in FOS value from 1.03 to 0.44 is noted, thus depicting the inefficiency of the tall wall under seismic loading conditions. Overall a hike of $47 \%$ in FOS values is registered on comparing the analysis of single-tier and two-tiered walls. Here, the two-tiered wall system emerges as a suitable alternative to the monolithic tall wall system. Hence, it can be suggested that if the need arises to erect a tall wall under seismic loading conditions, a two-tiered wall system is the most convenient substitute.

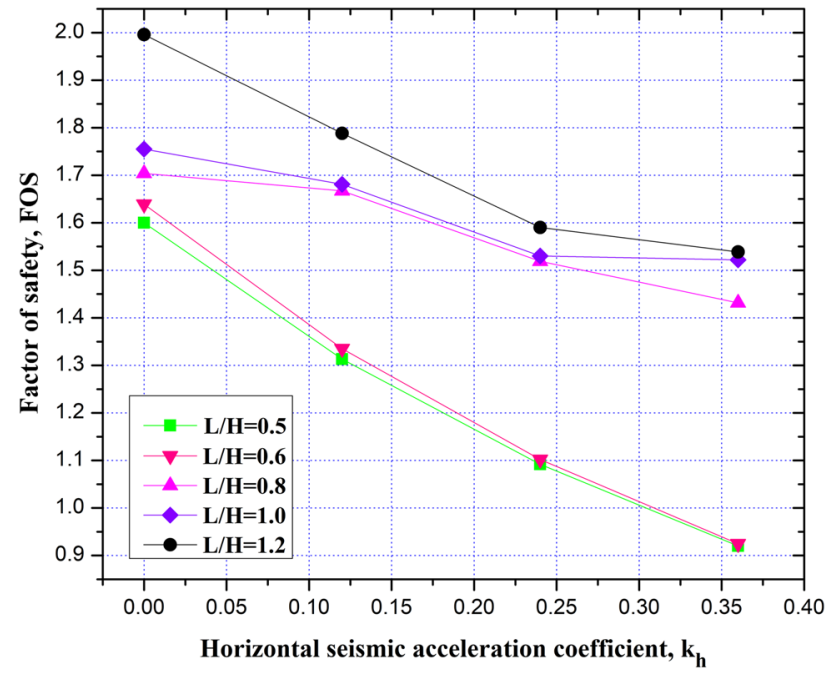

Fig. 4 Effect of variation of reinforcement length in two tiered wall system

\subsection{Effect of the variation of reinforcement length}

Figure 4 shows a graphical representation of the effect of reinforcement length on the FOS of the two-tiered wall system. It is observed that an increment in the reinforcement length agrees to the increased stability of the wall system. The FOS values are much higher when suitable and sufficient length of reinforcement is provided. The stability of the wall increases by $24 \%$ and $40 \%$ under gravity loading conditions and seismic loading conditions respectively, as the reinforcement length is increased from 0.5 to 1.2. Although the increased $k_{h}$ values inversely affect the performance of the MSE wall, yet the FOS values are adequate to construct a durable structure. A comparison of the optimum $\mathrm{L} / \mathrm{H}$ ratio for various horizontal ground acceleration coefficient level for conventional and two-tier MSE retaining walls is presented in Table 2.

\subsection{Potential failure planes}

The critical failure planes which were observed under gravity loading and seismic loading are presented in Figs. 5 and 6 for single-tiered and two-tiered walls, respectively. In the case of a single-tier wall, the observed critical failure plane originated at the corner of the leveling pad, with a high-stress zone below the leveling pad. This

Table 2 Comparison of the optimum $L / H$ ratio for various horizontal ground acceleration coefficient level for conventional and twotier MSE retaining walls

\begin{tabular}{lll}
\hline $\begin{array}{l}\text { Horizontal ground } \\
\text { acceleration coef- } \\
\text { ficient, } k_{\mathrm{h}}\end{array}$ & $\begin{array}{l}\text { Optimum } L / H \text { ratio } \\
\text { for conventional } \\
\text { MSE retaining wall }\end{array}$ & $\begin{array}{l}\text { Optimum } L / H \text { ratio for } \\
\text { two-tier MSE retaining } \\
\text { wall }\end{array}$ \\
\hline 0 & 1.2 & 0.8 \\
0.12 & 1.2 & 0.8 \\
0.24 & 1.2 & 0.9 \\
0.36 & 1.2 & 1.0 \\
\hline
\end{tabular}

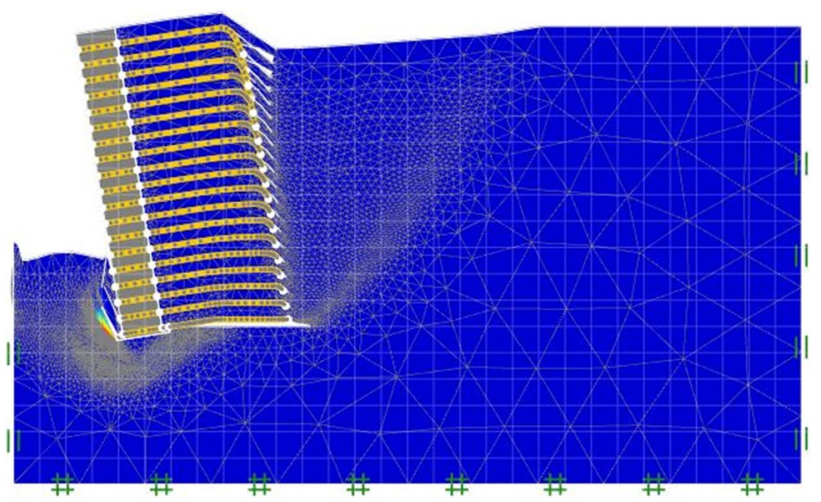

Fig. 5 General propagation of failure plane observed in single tiered wall system 


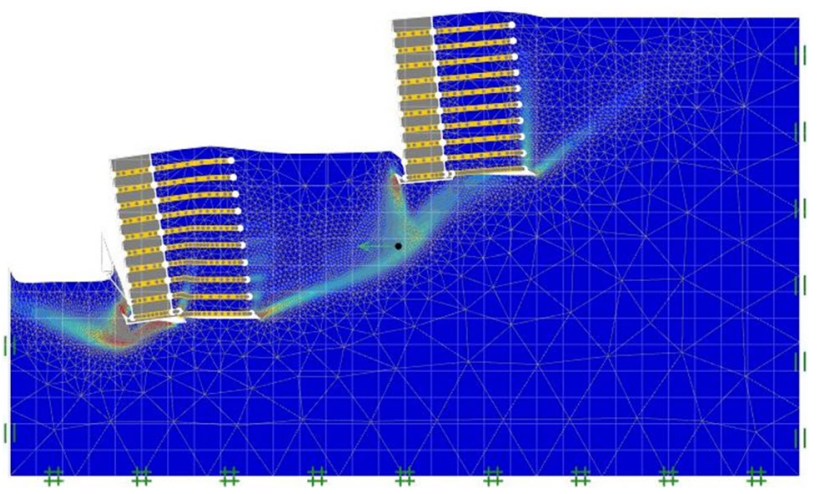

Fig. 6 General propagation of failure plane observed in two tiered wall system

particular behavior may be attributed to the fact that with an increase in the reinforcement length, the overall width of reinforced soil mass increases acting as a single unit. When the whole massive reinforced zone moves laterally away from the backfill, a high stressed zone is generated below the leveling pad. In the case of the two-tiered MSE wall, the critical failure plane propagates from the end of reinforcements provided at the base of the wall. A combined failure plane passes below the walls and meets at the end of the reinforcement layers in each wall, further extending towards the backfill surface. One more prominent effect of change in reinforcement length is observed that with an increase in the length of reinforcement, a clear gap between the end of reinforcement in lower-tier wall and leveling pad of the upper-tier wall gets decreases, which makes them behave like a single unit as mentioned in FHWA. Furthermore, when this clear gap decreases, the upper-tier wall, which is just above the lower tier wall, acts as a static surcharge to the lower wall due to its proximity and subsequently increases the stresses in the bottom portion of the lower tier. This overall scenario creates a single critical failure plane that is being originated just below the leveling pad of the lower tier. Moreover, a curved shear failure zone also can be seen below the leveling pad of the lower tier. At lower reinforcement lengths, critical failure planes are observed at the ends of the reinforcement length encased in the backfill soil, like the previous case (walls under gravity loading). However, a triangular wedge shear failure formation observed in the case of two-tiered MSE walls below the upper tier wall.

\section{Conclusions}

The present study observes the stability of the reinforced soil retaining wall and its potential modes of failure with the variation of geogrid length for the conventional and two-tiered MSE retaining walls. It is observed that the soil mass beneath the offset distance does not intersect the failure path in case of tiered MSE retaining wall, thus justifying the fact that after a calculated offset distance the walls exert no influence over each other. Also in the conventional MSE retaining wall, it is noted that with increases in the amplitude of seismicity (seismic ground acceleration coefficient) causes disturbance in the soil below the leveling pad rather than the soil reinforced in between the geogrid, which made the leveling pad to sinks before any failure occurs in the reinforced zone. In the case of two-tiered MSE retaining walls, it is observed that as the seismicity increases the failure pattern shows a more definite wedge-like geometry. The failure begins at the toe and propagates towards the backfill. In conventional MSE retaining wall failure also occurs at the end of the geosynthetic layer further propagating towards the backfill. Moreover, some distinctive conclusions drawn from the study are mentioned as follows:

(1) The factor of safety (FOS) values are found to be greater for two-tiered MSE retaining walls compared to a single-tiered MSE wall, registering a rise of around $47 \%$ in FOS than conventional MSE retaining walls. Therefore, it is suggested that whenever the need arises due to geological or topographical restraints, it safe and convenient to construct twotiered MSE retaining walls as an alternative, owing to their benefits.

(2) The optimum length of reinforcement required for achieving a satisfactory factor of safety in twotiered walls is much lesser than the optimum length required for achieving the same FOS in conventional MSE retaining walls. The study suggests an optimum reinforcement length of $0.8 \mathrm{H}$ for non-seismic loading conditions and $1.1 \mathrm{H}$ for seismic loading conditions for the safe design of the MSE wall. The suggestions so delivered, agrees to the criterion set by FHWA.

(3) This study observes that in monolithic walls the failure plane propagates from the toe of the wall and stresses are developed near the toe. With an increase in seismicity, the force on the geosynthetic layer is also increased. The stresses are also developed in between the geosynthetic layer and the backfill. In the case of two-tiered walls, the failure plane propagates from the toe to the backfill in a wedgelike structure. The geosynthetic layer is not much affected.

(4) The study also proves the efficiency of the two-tiered MSE walls under seismic loading conditions, as the two-tiered wall system performs better than the single-tiered wall at the highest level of seismic excitation, still comfortably crossing the given criterion, 
therefore suggesting the construction of two-tiered wall system under seismic loading conditions.

Acknowledgement The authors of this article gratefully acknowledge the anonymous reviewers for their critical comments which has helped the authors to improve the manuscript substantially. The remarks of the reviewers with their valuable inputs and suggestions have proven very beneficial in the further perfection of the former draft of the manuscript.

\section{Compliance with ethical standards}

Conflict of interest On behalf of all authors, the corresponding author states that there is no conflict of interest.

\section{References}

1. Bhattacharjee A, Amin MU (2019) Behaviour of two-tiered geosynthetic-reinforced soil walls. INAE Lett 4:91-100. https://doi. org/10.1007/s41403-019-00069-7

2. Leshchinsky D, Han J (2004) Geosynthetic reinforced multitiered walls. J Geotech Geoenviron Eng 130(12):1225-1235. https:// doi.org/10.1061/(ASCE)1090-0241(2004)130:12(1225)

3. Liu H, Yang G, Ling HI (2014) Seismic response of multitiered reinforced soil retaining walls. Soil Dyn Earthq Eng 61-62:1-12. https://doi.org/10.1016/j.soildyn.2014.01.012

4. Berg RR, Christopher BR, Samtani NC (2009) Design and construction of mechanically stabilized earth walls and reinforced soil slopes. US Department of Transportation Federal Highway Administration, National Highway Institute, Washington, DC, USA

5. NCMA (2012) Design manual for segmental retaining walls. In: Collin J (eds) $3^{\text {rd }}$ Edition, National Concrete Masonry Association, Herndon

6. AASHTO (2012) LRFD bridge design specifications. Customary U.S. Unit American Association of State Highway and Transportation Officials, Washington, DC, USA

7. Sankey JE, Soliman A (2004) Tall wall mechanically stabilized earth applications. Geotech Eng Transp Proj. https://doi. org/10.1061/40744(154)211

8. Ojha R, Chauhan VB (2019) Performance of geosynthetic reinforced segmental retaining walls. In: Shehata $\mathrm{H}$, Brandl $\mathrm{H}$, Bouassida M, Sorour T (eds) Sustainable thoughts in ground improvement and soil stability, GeoMEast 2019. Springer, Berlin, pp 196-206. https://doi.org/10.1007/978-3-030-34184-8_13

9. Kongkitkul W, Tatsuoka F, Hirakawa D, Sugimoto T, Kawahata S, Ito $M(2010)$ Time histories of tensile force in geogrid arranged in two full-scale high walls. Geosynth Int 17(1):12-32. https:// doi.org/10.1680/gein.2010.17.1.12

10. Wu JTH (2019) Geosynthetic reinforced soil (GRS) walls. Wiley, New York

11. OPTUM G2 (2020). Finite Element Program for Geotechnical Analysis, Optum Computational Engineering, www.optum ce.com. Accessed 1 Feb 2020

Publisher's Note Springer Nature remains neutral with regard to jurisdictional claims in published maps and institutional affiliations. 